\title{
Effects of recombinant human endostatin on the expression of vascular endothelial growth factor in human gastric cancer cell line MGC-803
}

\author{
YU-BIN WANG, JUN-HONG LIU and ZONG-MIN SONG \\ Department of General Surgery, The First Affiliated Hospital, Liaoning Medical University, Jinzhou 121001, P.R. China
}

Received July 2, 2012; Accepted August 8, 2012

DOI: $10.3892 /$ br.2012.3

\begin{abstract}
The present study aimed to explore the effects of recombinant human endostatin, endostar (ES), on the expression of vascular endothelial growth factor (VEGF) in the human gastric cancer cell line MGC-803. The expression of VEGF protein in MGC-803 cells was examined using immunohistochemistry. Subsequent to treatment with various concentrations of ES, the mRNA and VEGF protein expressions were determined in MGC-803 cells. A high level of VEGF protein expression was detected in MGC-803 cells. Subsequent to ES treatment, the mRNA and VEGF protein expressions were significantly decreased in MGC-803 cells (all $\mathrm{P}<0.05$ ). In conclusion, ES is likely to inhibit the VEGF expression in MGC-803 cells.
\end{abstract}

\section{Introduction}

Vascular endothelial growth factor (VEGF), an important angiogenic rate limiting factor, combined with its specific receptors, VEGFR-1 and VEGFR-2, may stimulate vascular endothelial cell proliferation promoting the formation of blood and lymphatic vessels, tumor growth and metastasis (1). Being a vascular solid malignant tumor, the biological behaviors of gastric cancer progression and metastasis depend on neovascularity (2). High levels of VEGF protein expressions have been confirmed in the human gastric cancer MGC-803 cell line (3). Endostar (ES), an anti-angiogenetic drug, inhibits tumor angiogenesis by reducing VEGF protein levels. This study aimed to examine the effects of ES on the VEGF expression in MGC-803 cells.

\section{Materials and methods}

Study approval. The present study was approved by the ethics committee of the First Affiliated Hospital of the Liaoning

Correspondence to: Dr Yu-Bin Wang, Department of General Surgery, The First Affiliated Hospital, Liaoning Medical University, No. 5, Section 3, Guta, Jinzhou 121001, P.R. China

E-mail: zf.23380681@163.com

Key words: recombinant human endostatin, gastric cancer, vascular endothelial growth factor
Medical University. The subjects enrolled in the study provided written formal consent.

Materials. The MGC-803 cell line was purchased from the Cell Bank, Shanghai Institute of Life Sciences, Chinese Academy of Sciences (Shanghai, China). RPMI-1640 culture medium and fetal bovine serum (FBS) were purchased from Gibco (Carlsbad, CA, USA). TRIzol reagent and the RT-PCR kit were purchased from Takara (Shiga, Japan). PV two-step immunocytochemistry kit was purchased from Zhongshan Golden Bridge (Beijing, China). Rabbit anti-human VEGF monoclonal antibody, horseradish peroxidase-labeled secondary antibody (goat anti-rabbit HRP-IgG) and $\beta$-actin were purchased from Santa Cruz Biotechnology, Inc. (Santa Cruz, CA, USA). ES (15 mg/3 ml/ampoule containing 3x10 units) was donated by Maidejing Company (Yantai, China). Primers were designed and synthesized by Takara.

Cell culture. MGC-803 cells were cultured in RPMI-1640 culture medium containing $10 \%$ of $\mathrm{FBS}$ at $37^{\circ} \mathrm{C}$ in a $5 \% \mathrm{CO}_{2}$ atmosphere. When the growing cells covered $80 \%$ of the bottom area of the culture bottle, the cells were digested with $0.25 \%$ of trypsin at $37^{\circ} \mathrm{C}$ for $1 \mathrm{~min}$. The cells were washed with phosphate-buffered saline (PBS) followed by the addition of fresh culture medium. Mechanical blow allowed cells into single cell suspension for passage. The cells of passage 5 were stored until use.

VEGF expression examined using immunocytochemistry. The cells were cultured until cell growth reached a single-layer, and then fixed with cold acetone. The primary antibody, rabbit antihuman VEGF monoclonal antibody, was diluted according to 1:50 with PBS. At the same time, PBS served as the negative control instead of VEGF. The secondary antibody, goat antirabbit HRP-IgG was diluted according to 1:200. Staining was performed with DAB. The slides were then sealed with gum. In case of brown particles in the cytoplasm and cell membrane, VEGF protein was considered present in gastric cancer cells.

VEGF mRNA expression detected with RT-PCR. MGC-803 cells were divided into 4 groups ( $\mathrm{n}=8$ /group). The MGC-803 cells in the 4 groups were cultured in RPMI-1640 culture medium, respectively, containing 1,10 or $20 \mu \mathrm{g} / \mathrm{ml}$ of ES and ES-free RPMI-1640 culture medium at $37^{\circ} \mathrm{C}$ in a $5 \% \mathrm{CO}_{2}$ 


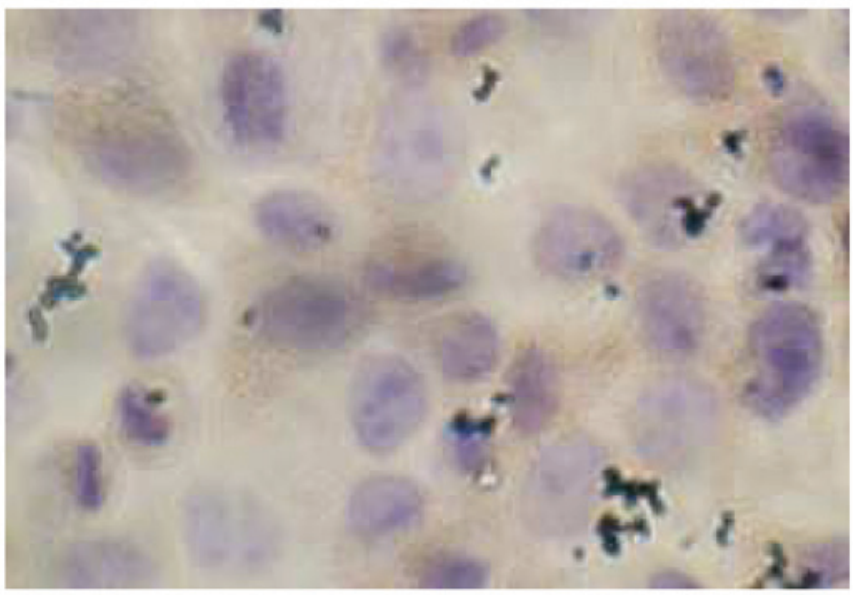

Figure 1. Brown particles are the protein expression of vascular endothelial growth factor in cytoplasm.

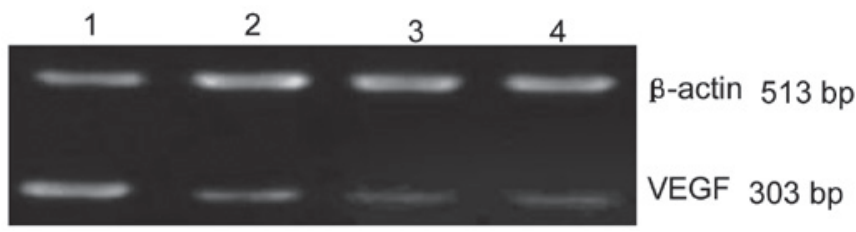

Figure 2. RT-PCR indicates that the mRNA expression of the vascular endothelial growth factor was negatively associated with ES in MGC-803 cells. Lane 1, control group; lane 2,1 $\mu \mathrm{g} / \mathrm{ml}$ of ES group; lane $3,10 \mu \mathrm{g} / \mathrm{ml}$ of ES group and lane $4,20 \mu \mathrm{g} / \mathrm{ml}$ of ES group.

atmosphere for $24 \mathrm{~h}$. After cells were collected, total RNA was extracted and RT-PCR was performed, according to the manufacturer's instructions. RT-PCR conditions were as follows: predenaturation at $95^{\circ} \mathrm{C}$ for $10 \mathrm{~min}$, denaturation at $94^{\circ} \mathrm{C}$ for $1 \mathrm{~min}$, reannealing at $60^{\circ} \mathrm{C}$ for $1 \mathrm{~min}$, elongation at $72^{\circ} \mathrm{C}$ for 2 min, 30 cycles, and a final elongation at $72^{\circ} \mathrm{C}$ for $8 \mathrm{~min}$. VEGF primers used were: upstream: 5'-GAAGTGGTGAAGTTCATGGATGTC-3' and downstream: 5'-CGATCGTTCTGTATCACTCTTTCC-3'. PCR products underwent agarose gel electrophoresis and image scanning was performed, while analysis was carried out using the Lab Works software. The average gray values of positive electrophoretic bands were determined, and the average gray value sample: $\beta$-actin ratio was determined as the relative expression level of VEGF mRNA.

Western blotting used to determine VEGF protein. MGC-803 cells were divided into 4 groups ( $\mathrm{n}=8 /$ group). The MGC- 803 cells in the 4 groups were cultured at $37^{\circ} \mathrm{C}$ in a $5 \% \mathrm{CO}_{2}$ atmosphere for $24 \mathrm{~h}$, in RPMI-1640 culture medium containing 1 , 10 or $20 \mu \mathrm{g} / \mathrm{ml}$ of ES and ES-free RPMI-1640 culture medium, respectively. The cells were collected, washed three times with cold PBS followed by the addition of $400 \mu 1$ of lysate, and placed on ice for $30 \mathrm{~min}$. Subsequent to centrifugation at a rate of $14,000 \mathrm{rpm}$ for $5 \mathrm{~min}$ at $4^{\circ} \mathrm{C}$, the supernatant was collected to determine the protein concentration followed by SDS-PAGE and the transmembrane, and then sealed with tris-buffered saline tween-20 (TBST) containing 5\% of bovine serum albumin (BSA) at room temperature for $1 \mathrm{~h}$. The antibodies of

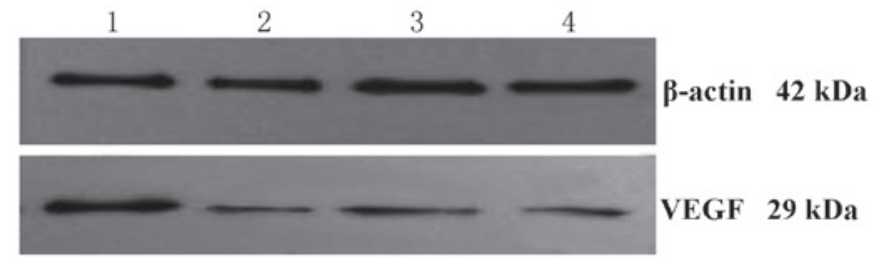

Figure 3. Western blotting indicates the protein expression of the vascular endothelial growth factor was negatively associated with ES in MGC-803 cells. Lane 1, control group; lane 2, $1 \mu \mathrm{g} / \mathrm{ml}$ of ES group; lane $3,10 \mu \mathrm{g} / \mathrm{ml}$ of ES group and lane $4,20 \mu \mathrm{g} / \mathrm{ml}$ of ES group.

VEGF and $\beta$-actin were added, respectively, at $4^{\circ} \mathrm{C}$ overnight, followed by the secondary antibody, HRP-IgG $(1: 1,000)$. The films were then washed and the relative expression level of VEGF protein was analyzed using the gel imaging system.

Statistical analysis. Statistical analysis was carried out using the SPSS 16.0 software. The measurement data were indicated as the mean $\pm \mathrm{SD}$. Single factor analysis was used for the comparison between groups. $\mathrm{P}<0.05$ was considered to indicate a statistically significant difference.

\section{Results}

VEGF protein expression in MGC-803 cells. Immunohistochemistry indicated a high level of VEGF protein expression in cytoplasm in the MGC-803 cells (Fig. 1).

Effects of ES on VEGF $m R N A$. RT-PCR indicated that the relative expression levels of VEGF mRNA in 1,10 and $20 \mu \mathrm{g} / \mathrm{ml}$ of ES and the control groups were $0.47 \pm 0.06,0.24 \pm 0.03,0.17 \pm 0.05$ and $0.92 \pm 0.03$, respectively. Statistically significant differences were detected in ES and the control groups (all $\mathrm{P}<0.05$ ), demonstrating that ES markedly decreased the level of VEGF mRNA in MGC-803 cells. Statistically significant differences were detected in the ES groups (all $\mathrm{P}<0.05$ ), demonstrating that the level of VEGF mRNA expression is negatively associated with the dose of ES (Fig. 2).

Effects of ES on VEGF protein. Result of the western blotting indicated that the relative expression levels of VEGF protein in 1,10 and $20 \mu \mathrm{g} / \mathrm{ml}$ of ES and the control groups were $0.75 \pm 0.03,0.37 \pm 0.07,0.21 \pm 0.06$ and $2.23 \pm 0.14$, respectively. Statistically significant differences were detected in the ES and the control groups (all $\mathrm{P}<0.05)$, demonstrating that ES markedly decreased the level of VEGF protein in MGC-803 cells. Statistically significant differences were detected in ES groups $(\mathrm{P}<0.05)$, demonstrating that the level of VEGF protein is negatively associated with the dose of ES (Fig. 3).

\section{Discussion}

Tumor growth and metastasis are based on angiogenesis, while VEGF is an important regulatory factor of neovascularization. In various types of gastric cancer tissues, the mRNA and VEGF protein expressions are positive or strongly positive, higher compared to healthy gastric tissues (4). Microvascular density is significantly higher in gastric cancer tissues, espe- 
cially in strongly VEGF-positive tissues, compared to healthy gastric tissues, demonstrating that VEGF is closely correlated with neovascularization in gastric cancer tissues and promotes gastric cancer growth and metastasis. In this study, MGC-803 cells derived from poorly-differentiated gastric adenocarcinoma were used, due to their high malignancy and VEGF expression level.

ES, a broad-spectrum angiogenesis inhibitor (5), blocks the combination of VEGF through its receptors and inhibits VEGF biological activities, such as signal transduction of blood and lymphatic vessel formation and the survival, proliferation and migration of epithelial cells (6). Therefore, neovascularization was decreased, whereas the blood supply to the tumor was reduced, inhibiting tumor growth (7).

In this study, after MGC-803 cells were directly treated with ES, immunohistochemistry indicated the presence of a large amount of VEGF protein in MGC-803 cells. The results of RT-PCR suggested that ES significantly decreased VEGF mRNA, and with the increase in ES, VEGF mRNA was decreased. The decreased VEGF mRNA affected the downstream protein translation and reduced the specific protein confirmed by western blotting. ES also reduced VEGF protein, thus increasing ES. VEGF is mainly secreted by tumor and neovascular endothelial cells, while being markedly involved in neovascularization, tumor growth and metastasis. Therefore, in theory, blocking neovascularization inhibits tumor growth, while improving the general status of patients and extending their survival period. ES has been confirmed to interfere with the combination of VEGF through its receptors to inhibit tumor growth and metastasis (8). ES also exhibited positive effects in II or III clinical trials of breast and hepatic cancer. In MGC-803 cells, ES inhibited tumor growth and metastasis possibly through a reduction of the formation of blood and lymphatic vessels, requiring additional in vivo experiments to be confirmed.

\section{Acknowledgements}

This study was financed by grants from the Department of Education of Liaoning (no. 2009A443).

\section{References}

1. He XW, Yu X, Liu T, Yu SY and Chen DJ: Vector-based RNA interference against vascular endothelial grow th factor $C$ inhibits tumor lymph angiogenesis and growth of colorectal cancer in vivo in mice. Chin Med J (Engl) 121: 439-444, 2008.

2. Satchi-Fainoaro R, Puder M, Davies JW, Tran HT, Sampson DA, Greene AK, Corfas G and Folkman J: Targeting angiogenesis with a conjugate of H PMA copolymer and TNP-470. Nat Med 10: 255-261, 2004.

3. Tian XJ, Wu J and Meng L: Preparation of monoclonal antibodies to human vascular endothelial growth factor (VEGF 121) and identification of its expression on gastric carcinoma cell line MGC803. Zhonghua Zhong Liu Za Zhi 21: 93-95, 1999 (In Chinese)

4. Luo XD, Xin Y and Xiao YP: Expression of VEGF and its receptors Flt-1 and KDR in gastric carcinoma and its significance. J Chin Med Univ 37: 760-763, 2008 (In Chinese).

5. Xu HR, Tian W, Niu XH, Yuan RY, Zhang Q, Chen DF and Liu WF: In vitro study of recombinant human endostatin in combination with adriamycin on human osteosarcoma cell OS-732. Chin J Bone Tumor Bone Dis 7: 129-132, 2008 (In Chinese).

6. Neskey DM, Ambesi A, Pumiglia KM and McKeown-Longo PJ: Endostatin and anastellin inhibit distinct aspects of the angiogenic process. J Exp Clin Cancer Res 27: 61, 2008.

7. Wu XZ: New strategy of antiangiogenic therapy for hepatocellular carcinoma. Neoplasma 55: 472-481, 2008.

8. Franco TH, Khan A, Joshi V and Thomas B: Takotsubo cardiomyopathy in two men receiving bevacizumab for metastatic cancer. Ther Clin Risk Manag 4: 1367-1370, 2008. 